\title{
COMMENTS ON A PREVIOUS NOTE (RHIC-I) ABOUT INTRABEAM SCATTERING CALCULATION \\ FOR BUNCHED BEAMS IN COLLIDNG MODE
}

\author{
A.G. Ruggiero
}

(BNL, November 19, 1983) 
$-1$

There is a mistake in RHic-1 note. For the long bumbles colliding mode the peak current is

$$
I=\frac{N_{c} e \beta_{c}}{\sqrt{2 \pi} \sigma_{c}}
$$

where

$$
\begin{aligned}
& N_{c} \text {, number of partides/lunch }=6 \times 10^{10} \\
& \sigma_{e} \text {, rms bunch length }=50 \mathrm{~m}
\end{aligned}
$$

As correctly stated in page 7 of the note

$$
I=0.023 \text { Amp-partide }
$$

and this muller was wed throughout all the rest of the calarkation except when we come to th intrabeam scattering effects - At rage 9 we erroneously state tat the peak current at $\gamma=100$ is also the same than the average current at injection. By doing this we have underestimated the peak current by exactly a factor of 10. Therefore the diffusion rates 
$-2-$

for intraleam scattering at top energy shied all be modified as shown in th following table.

$$
\begin{array}{lll}
\varepsilon_{N}=4 \pi \mathrm{mm} \cdot \mathrm{mrad} & \gamma=100 \\
\gamma_{T} & t_{E} & t_{\beta} \\
10 & 0.15 \text { hours } & 1.1 \\
20 & 0.56 & 1.5 \\
30 & 0.8 & 2.0 \\
50 & 0.6 & 3.0 \\
80 & 20 & 5 .
\end{array}
$$

Unless $\gamma_{T}$ is very large the envy diffurain time are too short to be ace rested. Nevertheless the flowing points are worth of consideration.

(i) There is a strong dyandence of the deffer sion rates with 12 inial energy great. A time in regration is required to check how much actually the beam will grow over a grind of the bung mong (10-20 hours). 
$-3-$

(ii) Diffusion rates are quickly reduced by increasing the initial energy, spread. the spreads we have assumed dene are those at the limit of longitudinal stability - But it is josuille to ma. mijolate the bunches to larger Lunch area, and therefore do larger grads. How large can be tole initime energy spreads - I see three pare lime" rations:

(a) the AGS bucket area and I Lane already estivated toss requirement -

(b) The transition energy crossing (if any) inghicutious

(c) The size in $\Delta / p$ of the RF stacking requirements - 


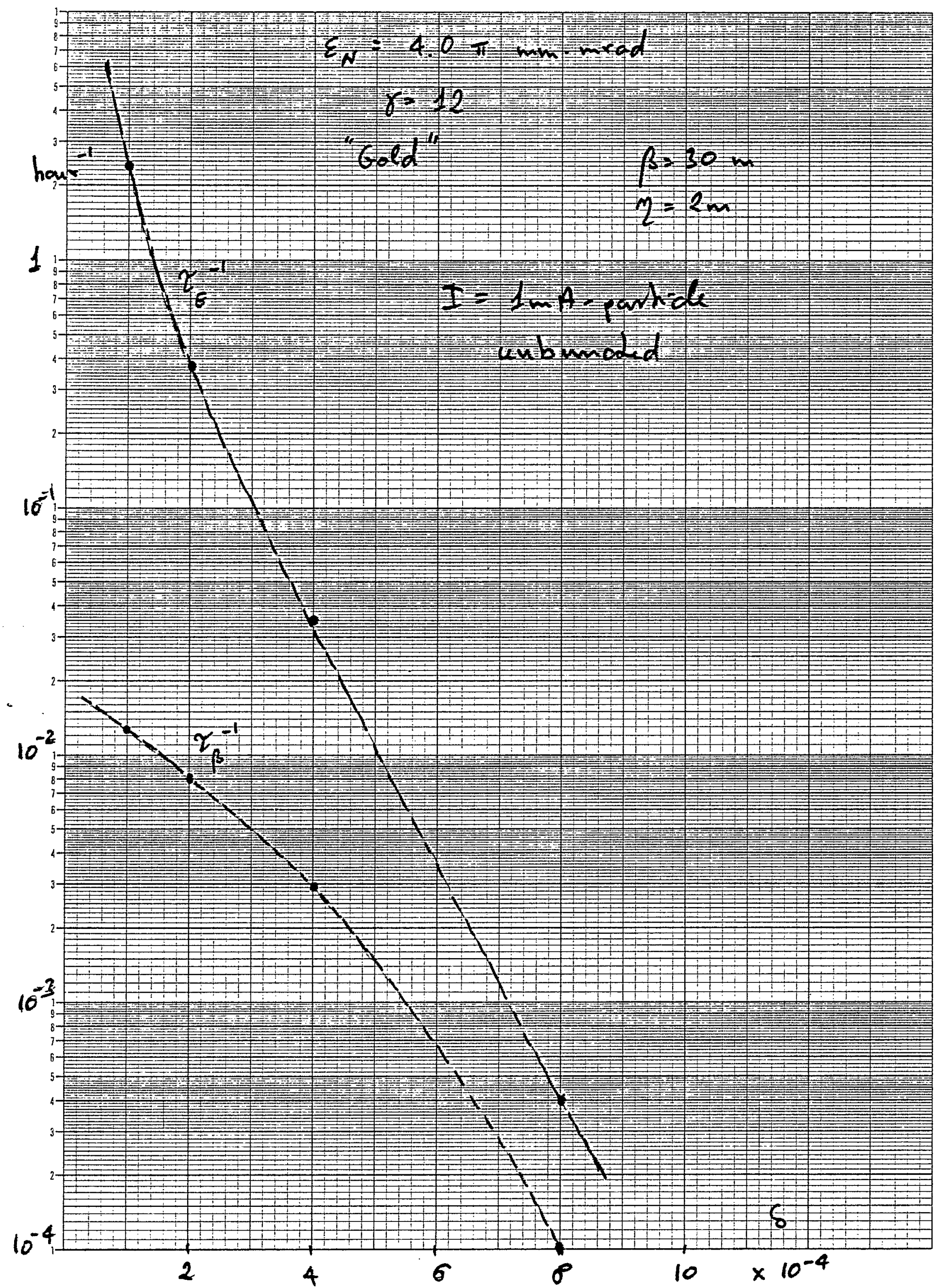




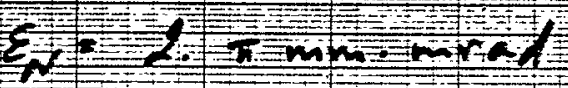

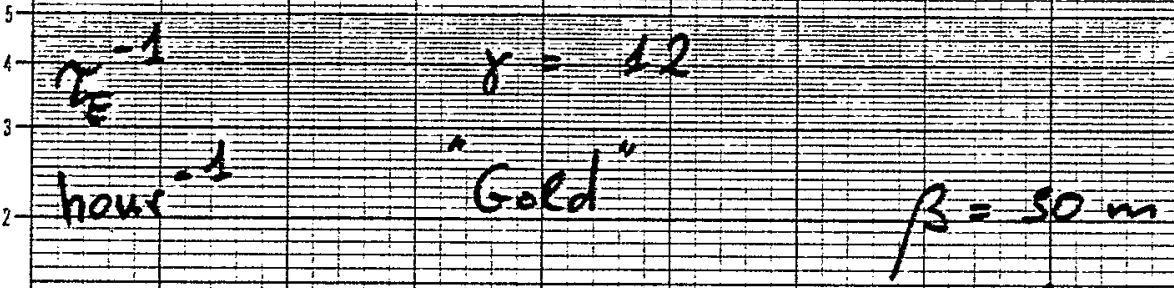

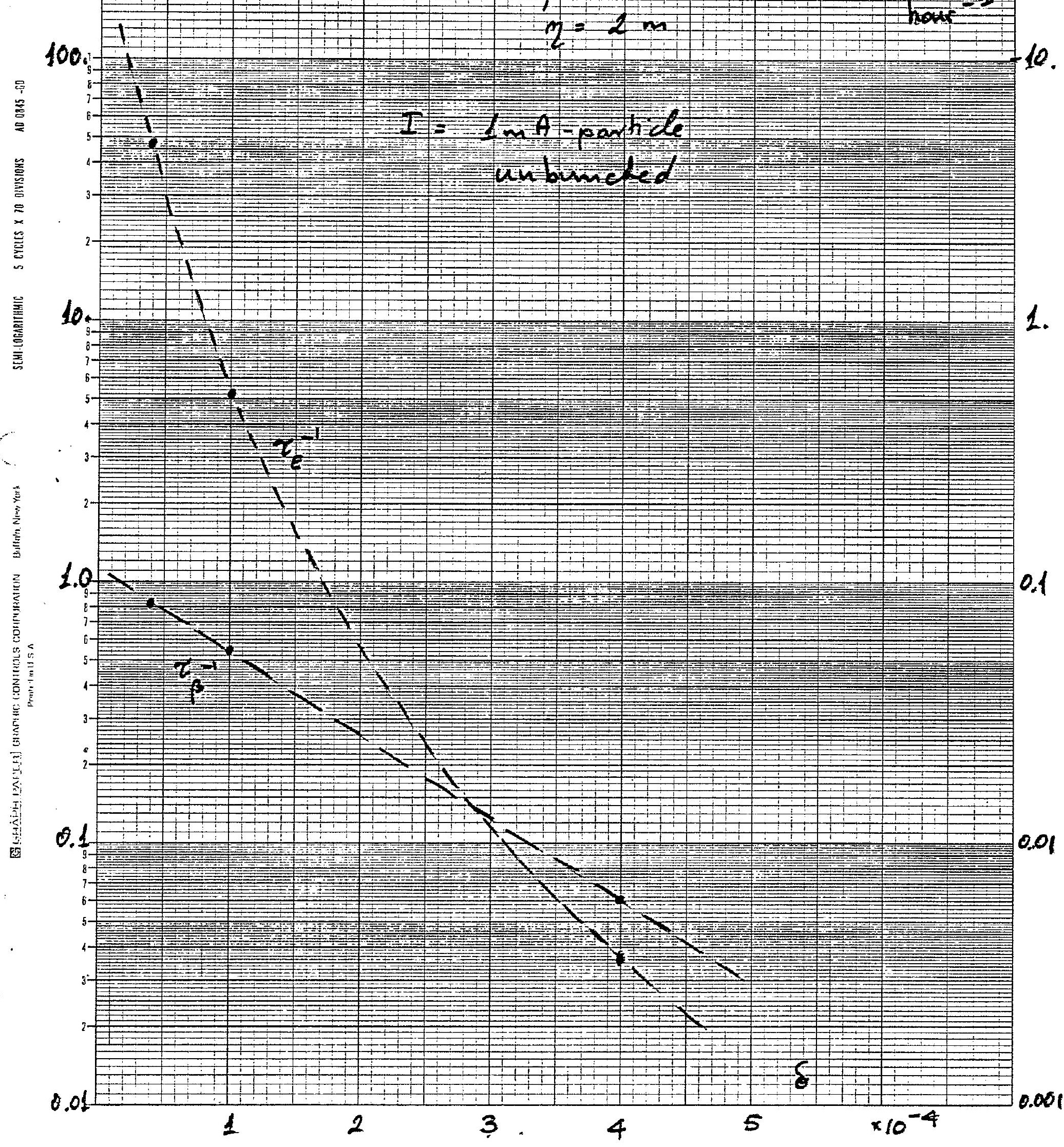




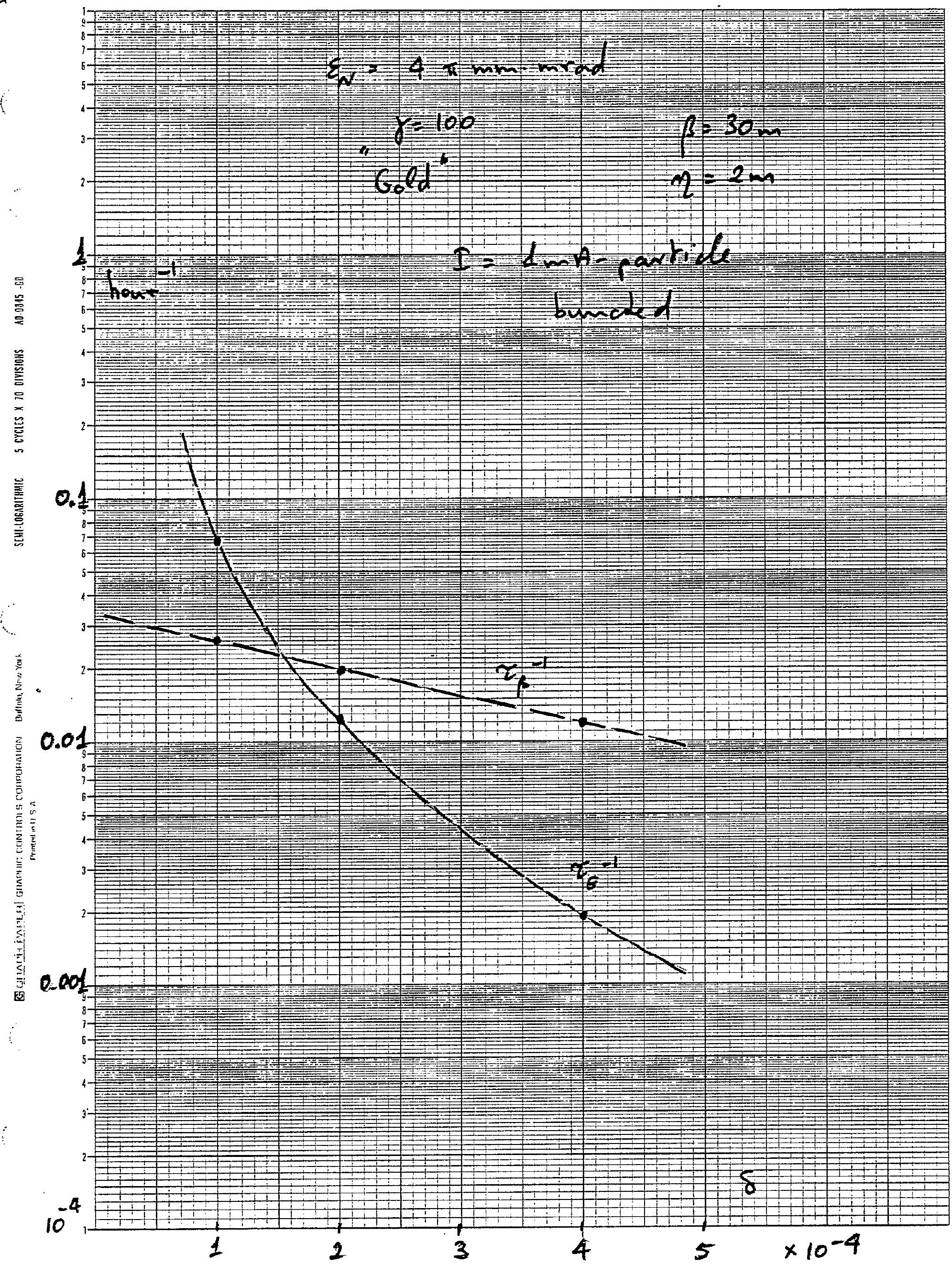

